\title{
Case-control study of the risk factors for age related macular degeneration
}

Gilles Chaine, Alain Hullo, José Sahel, Gisèle Soubrane, Marie-A Espinasse-Berrod, Denys Schutz, Christian Bourguignon, Catherine Harpey, Yves Brault, Maylis Coste, Dominique Moccatti, Hubert Bourgeois, for FRANCE-DMLA Study Group
Hôpital Avicenne, Bobigny

G Chaine

Centre Hospitalier Lyon-Sud, Pierre-Bénite A Hullo

Hôpital Civil, Strasbourg

J Sahel

Centre Hospitalier Intercommunal, Créteil

G Soubrane

Hôpital Necker, Paris M-A Espinasse-Berrod

Biopharma

D Schutz

Information Servier C Bourguignon

C Harpey

Division de Biométrie IRIS, Neuilly sur Seine Y Brault

M Coste

D Moccatti

Hôpital Val de Grâce, Paris, France

$\mathrm{H}$ Bourgeois

Correspondence to: Dr C Chaine, Hopital Avicenne, Service d'Ophtalmologie, 125 route de Stalingrad, 93000 Bobigny, France.

Accepted for publication 4 March 1998

\begin{abstract}
Aim-A case-control study was initiated to determine the risk factors for the development of age related macular degeneration (AMD).

Methods-Study participants, who were all white, aged 50-85 years, and were recruited from private ophthalmology practices. Each practitioner enrolled patients with bilateral AMD, who were then matched with controls for sex and age. Environmental factors and systemic and ocular histories were screened. All patients had bilateral red-free fundus photographs and fluorescein angiography. Photographs were classified into pigment epithelium alterations, drusen, geographic atrophy, and exudative AMD. Statistical analysis included the identification of risk factors for AMD. A multivariate analysis was performed at the end of the study. Analysis included the entire study population and was carried out for each stage of AMD.
\end{abstract}

Results-1844 controls were compared with 1844 patients with AMD. Mean age was 71 years for controls and 72 for cases. Logistic regression identified six major risk factors for AMD (whole population): arterial hypertension (odds ratio (OR) $=1.28)$, coronary disease $(O R=1.31)$, hyperopia $(O R=1.33)$, light coloured irises $(O R=1.22)$, and lens opacities or previous cataract surgery $(O R=1.55)$. The significance of vascular risk factors was increased for late stages of AMD, especially the atrophic forms (coronary disease, $\mathrm{OR}=3.19$ ).

Conclusions-This large case-control study confirms some of the risk factors previously identified and may contribute to the determination of methods for prevention of AMD.

(Br f Ophthalmol 1998;82:996-1002)

Age related macular degeneration (AMD) is the most common cause of blindness in people over 55 years of age in developed countries. The pathogenesis of this condition is still putative $^{1}$ and, in absence of therapy, there is a need to identify risk factors associated with AMD in an effort to preclude its development.

Following the Framingham Eye Study, ${ }^{2}$ a number of epidemiological studies have attempted to identify risk factors for AMD. ${ }^{2-23}$ These studies, which were case-control and population based, have provided informative but controversial data. The goals of the present study were to further explore the possible link between environmental factors and systemic and ocular conditions that may be risk factors for AMD in a European population.

Based upon previously published reports, we studied the following risk factors in a casecontrol study: present and past smoking habits, coronary artery disease, systemic hypertension, ametropia, iris colour, and lens status.

\section{Subjects and methods}

PARTICIPATION OF OPHTHALMOLOGISTS

Biopharma initiated this project and provided logistic and financial support with no financial interest.

The goals and methods of the study were presented to participating ophthalmologists $(n=859)$ at several regional meetings by members of the scientific committee and by regional coordinators.

INCLUSION AND EXCLUSION CRITERIA

Each ophthalmologist first had to select a day for recruitment. The first patient satisfying the inclusion criteria examined on this day or on the following day, was included. Inclusion criteria were bilateral AMD features: drusen (minimum of five in each eye), pigment epithelium alteration, geographic atrophy, or exudative maculopathy. Visual acuity was measured but not taken in account for inclusion. ${ }^{212}$ The corresponding control (that is, without any age related change) was the next patient seen after the AMD case who was of the same sex and of comparable age (plus or minus 5 years). Both controls and cases had to be white, nondiabetic, and 50-85 years of age. Cooperation and good photographic documentation of fundus status were required. The majority of the control group was seen for refractive problems; few of them had retinal problems, mainly arteriolosclerosis modifications (Table 1 ).

Table 1 Fundus pathology in the controls

\begin{tabular}{lc}
\hline Pathology & $\begin{array}{c}\text { No of } \\
\text { patients }\end{array}$ \\
\hline Central serous chorioretinopathy & 1 \\
Choroidal myopic abnormality & 11 \\
Inherited macular dystrophy & 7 \\
Acute multifocal placoid pigment epitheliopathy & 1 \\
Pseudophakic macular cystoid oedema & 5 \\
Epiretinal premacular membrane & 23 \\
Macroaneurysm & 2 \\
Branch vein occlusion & 37 \\
Central retinal venous occlusion & 22 \\
Hypertensive retinopathy or atherosclerosis & 187 \\
Parafoveolar telangiectasis & 1 \\
Toxoplasmosis & 2 \\
Macular hole & 2 \\
\hline
\end{tabular}




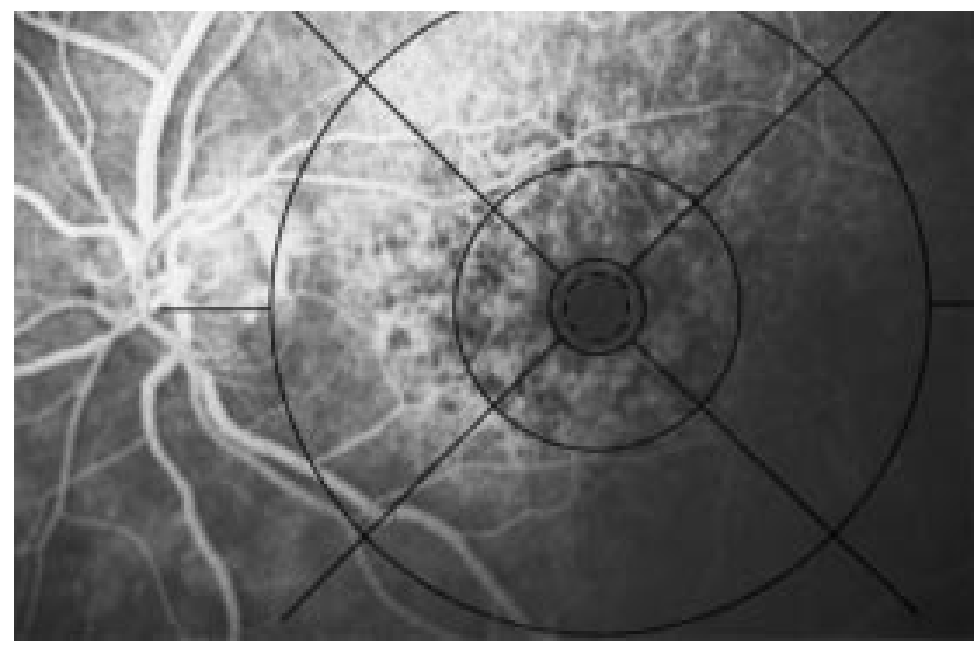

Figure 1 Simplified grid derived from the Wisconsin grid. The central area is localised inside the innermost continuous circle, the peripheral area is outside the inner circle.

\section{DATA COLLECTION}

Standardised questionnaire

The past or present professional activity, current medication use, and all major diseases (ophthalmological or systemic) were noted. The general practitioner was informed of the study, and gave written information on the systemic conditions and past and current medications. Angina pectoris was diagnosed by questioning the patient; infarction was diagnosed electrocardiographically. Hypertension was defined according to World Health Organisation guidelines. A hypertensive subject was thus defined as having a systolic blood pressure greater than $160 \mathrm{~mm} \mathrm{Hg}$ and/or a diastolic blood pressure greater than $95 \mathrm{~mm} \mathrm{Hg}$ at three separate measurements taken during at least two different consultations. The aim of antihypertensive treatment was to obtain a diastolic blood pressure less than or equal to $90 \mathrm{~mm} \mathrm{Hg}$.

All patients were asked questions about environmental or general factors using a standard questionnaire:

- Do you take medication for high blood pressure?

- Have you ever had heart disease, such as angina or a myocardial infarction?

- Do you smoke regularly?

If yes, since what age and how many cigarettes do you smoke a day?

If no, have you ever smoked previously (duration and amount)?

A complete ophthalmological examination was performed and results were recorded. Both eyes were studied and the eye with the worse distance visual acuity was included in the study. An eye was randomly chosen in case of equal acuity. Examination included optical correction, distance and reading acuity test (Monoyer and Parinaud charts), possible amblyopia, iris colour (light or dark; light iris colour included grey, blue, and green), and intraocular pressure. Mean distance visual acuity measured with a Monoyer chart (from 0 to 10) was right eye and left eye 4.3 (SD 3.2) for cases and right eye 7.4 and left eye 7.3 (2.5) for controls. An attempt was made to assess the presence or absence of lens opacities as well as the nuclear colour (white, yellow, or brown) and the localisation of the opacities (nuclear, cortical, or capsular). The time of cataract extraction and the type of correction (glasses, contact lenses, or intraocular lens) were recorded. Sixty three pairs with missing information were not included.

\section{Reading centre}

Photographic examination included red-free frames of both maculas and fluorescein angiography (FA) of both eyes of patients with AMD. Red-free or colour frames but not FA of both maculas were required for controls. FA was considered relevant for control. Centralised reading of the photographs was performed independently by three pairs of ophthalmologists (HB and GC; MAE-B and AH; JS and GS) after testing for interobserver and intraobserver classification consistency. A simplified grid derived from the Wisconsin grid was used to localise atrophic, hypopigmented, or hyperpigmented lesions. ${ }^{24} 25$ The slide of the grid was superimposed over the videoprojected fundus photographs. The centre of the circles corresponded to the centre of the macula and the outer circle was tangential to the temporal border of the optic disc (Fig 1).

All elementary lesions were assessed in the eye with the worse visual acuity and cases were divided into four different types according to the most severe or most extensive lesion ${ }^{26}{ }^{27}$ :

- Drusen (minimum of five for inclusion) were classified as hard or soft, and as isolated or confluent. ${ }^{28}$ Hard drusen, with sharp borders, corresponded to a window defect on FA; soft drusen had fuzzy edges and were characterised by delayed and late staining on FA. Controls were drusen free on fundus examination as well on red-free or colour frames.

- Pigment epithelium alterations included hypo- or hyperpigmentation or both. Hypopigmentation corresponded to a window defect that allowed observation of the choriocapillaris on FA. Hyperpigmentation was identified as granules or clumps of pigment in or beneath the retina that resulted in blocked fluorescence on FA. ${ }^{29}$

- Geographic atrophy (GA) appeared on ophthalmoscopy as sharply demarcated zones of decreased coloration with exposure of the underlying large choroidal vessels. These areas were hyperfluorescent on FA owing to a window defect. This form has been described as "the natural end result of AMD in the absence of clinical evidence of choroidal neovascularisation." ${ }^{30}$ Therefore, areas of retinal pigment epithelium (RPE) atrophy adjacent to a disciform scar were not considered to be "geographic atrophy", but rather RPE depigmentation. ${ }^{25-30}$

- Exudative maculopathy included macular serous detachment of the retina and/or RPE. On the red-free or colour frame, exudative macular degeneration was defined as the presence of a macular retinal serous detachment. This retinal serous detachment was associated with an RPE detachment, or with retinal, subretinal, and/or subRPE haemor- 
Table 2 Number of inclusions

\begin{tabular}{llllllll}
\hline & Total & $\begin{array}{l}\text { Inclusion of } \\
\text { 1 pair }\end{array}$ & $\begin{array}{l}\text { Inclusion of } \\
\text { 2 pairs }\end{array}$ & $\begin{array}{l}\text { Inclusion of } \\
\text { 3 pairs }\end{array}$ & $\begin{array}{l}\text { Inclusion of } \\
\text { 4 pairs }\end{array}$ & $\begin{array}{l}\text { Inclusion of } \\
5 \text { pairs }\end{array}$ & $\begin{array}{l}\text { Inclusion of } \\
\text { 6 pairs }\end{array}$ \\
\hline Participating ophthalmologists & 859 & 292 & 275 & 185 & 89 & 17 & 1 \\
\hline
\end{tabular}

rhage, and/or with hard exudates. No attempt was made to assess the presence of fibrous tissue.

According to FA features, choroidal new vessels (CNV) were subdivided into well defined $\mathrm{CNV}$, occult $\mathrm{CNV}$, and vascularised RPE detachment. Well defined CNV were characterised by early, bright choroidal hyperfluorescence with well demarcated boundaries. With progressive dye transit, the boundaries of well defined CNV became obscured by the rapid and extensive leakage and pooling of dye in the overlying subsensory retina. ${ }^{31}$ Occult CNV did not display discernible hyperfluorescence on early phase angiography. Frames of the mid and late phases, however, showed diffuse, mild leakage into the overlying subsensory retinal, often with punctate or stippled hyperfluorescence in the outer retina. ${ }^{32}$ The boundaries of this hyperfluorescence were poorly demarcated in most cases. ${ }^{33}$ Vascularised RPE detachments were suggested by colour and red-free photographs, and characterised by an uneven and delayed filling during the course of FA. The presence of CNV was indicated by an area of early localised and accentuated hyperfluorescence. If two types of $\mathrm{CNV}$ were present (that is, well defined CNV in a patch of occult $\mathrm{CNV}$ ), both were coded.

Table 3 Sex distribution by age group

\begin{tabular}{lrrrrrrrrr}
\hline \multicolumn{2}{l}{ Age (years) } \\
\cline { 2 - 7 } & $51-55$ & $56-60$ & $61-65$ & $66-70$ & $71-75$ & $76-80$ & $81-85$ & $86-89$ & Total \\
\hline Male & 7 & 17 & 47 & 181 & 122 & 118 & 73 & 3 & 568 \\
Female & 14 & 35 & 102 & 314 & 300 & 296 & 205 & 10 & 1276 \\
Total & 21 & 52 & 149 & 495 & 422 & 414 & 278 & 13 & 1844 \\
\hline
\end{tabular}

Table 4 Characteristics in relation to the stages of $A M D$

\begin{tabular}{lllll}
\hline & $\begin{array}{l}\text { Drusen } \\
(n=496)\end{array}$ & $\begin{array}{l}\text { Pigment } \\
\text { alteration } \\
(n=333)\end{array}$ & $\begin{array}{l}\text { Geographic } \\
\text { atrophy } \\
(n=343)\end{array}$ & $\begin{array}{l}\text { Exudative } \\
\text { maculopathy } \\
(n=672)\end{array}$ \\
\hline Age (years) & 71.1 & 72.1 & 74.8 & 74.0 \\
Sex (\% women) & 73.2 & 66.4 & 72.0 & 66.2 \\
Drusen (\%): & 99.6 & 77.2 & 72.6 & 54.6 \\
Small hard & 69.0 & 48.3 & 42.6 & 27.5 \\
Large hard & 88.9 & 64.0 & 63.0 & 47.2 \\
Soft & 54.8 & 27.9 & 26.8 & 12.1 \\
Soft and confluent & 31.5 & 10.5 & 10.2 & 5.5 \\
Pigment epithelium detachment & 2.8 & - & - & 15.5 \\
Pigmentation alterations: & 27.2 & 94.3 & 13.4 & 11.9 \\
Hypopigmentation (\%) & 5.4 & 35.4 & 3.8 & 4.0 \\
Involving the foveola & 16.5 & 82.6 & 8.7 & 9.1 \\
Macular, not involving the foveola & 26.0 & 89.5 & 12.5 & 10.9 \\
$\quad$ Extramacular & 36.1 & 83.8 & 65.6 & 31.5 \\
Hyperpigmentation (\%) & 12.1 & 33.9 & 23.0 & 10.6 \\
$\quad$ Involving the foveola & 22.8 & 72.1 & 45.5 & 21.6 \\
Macular, not involving the foveola & 29.8 & 80.5 & 63.0 & 29.5 \\
$\quad$ Extramacular & - & - & 98.5 & - \\
Atrophy (\%): & - & - & 67.6 & - \\
Involving the foveola & - & - & 91.5 & - \\
Macular, not involving the foveola & - & - & 96.5 & - \\
Extramacular & - & - & - & 98.2 \\
CNV (\%): & - & - & - & 30.1 \\
Involving the foveola & & - & - & 72.0 \\
Macular, not involving the foveola & - & & & \\
\hline & & & - & - \\
\hline
\end{tabular}

For every subtype of lesion, the term "non-applicable" was used when the lesion was either obscured or poorly identifiable.

With projection of the modified grid onto fundus photographs and angiograms, the lesions were classified topographically as peripheral (sparing the inner circle) or central (encroaching upon the inner circle), independently of the involvement of the centre of the macula.

\section{POPULATION}

Each participating ophthalmologist provided up to six cases and as many controls; 1844 pairs were included by 859 participating ophthalmologists evenly distributed throughout France (Table 2).

Mean age was 73 years (range 53-89) for AMD patients and 72 (range 51-89) for controls. Males accounted for $31 \%$ of cases and females for $69 \%$ (Table 3). Cases were divided into 496 drusen, 333 pigment epithelium alterations, 343 geographic atrophy, and 672 exudative maculopathy (Table 4).

\section{STATISTICAL METHOD}

A 1-1 matched case-control study was designed by stratifying inclusions on the basis of age, sex, and referring ophthalmologist.

The relation between hypothesised risk factors (explanatory or independent variables) and the outcome of AMD (dependent variable) was investigated. All explanatory variables of this study were dichotomous or polychotomous with three or four categories. Dichotomous variables were systemic hypertension and coronary disease, and the reference group was defined as the absence of the disease. Design variables were created to represent the categories of the polychotomous variables. For smoking, spherical equivalent, iris colour, lens opacities, and/or cataract surgery statistical models were built using respectively non-smoking, emmetropia, dark iris, no lens opacities, and no cataract surgery as reference groups.

Results are expressed in terms of odds ratio (OR) with a $95 \%$ confidence interval.

For matched case-control studies, conditional maximum likelihood estimates of the OR must be computed. ${ }^{34}$ Such estimates were obtained using standard logistic regression software (Statistical Analysis System).

The selection of variables followed three steps specified hereafter, considering $5 \%$ as the significance level for type I error rate:

- The selection process began with an univariate analysis of each variable. Any variable whose univariate test (Wald statistic) was significant was considered as a candidate for the multivariable model.

- For variables associated with the outcome of AMD, a second step investigated the relation 
Table 5 Analysed risk factors in the study population

\begin{tabular}{|c|c|c|c|c|}
\hline & \multicolumn{4}{|c|}{ Total population } \\
\hline & \multicolumn{3}{|c|}{ Univariate analysis } & \multirow{2}{*}{$\begin{array}{l}\text { Multivariate } \\
\text { analysis OR } \\
(95 \% \text { CI) }\end{array}$} \\
\hline & $\begin{array}{l}A M D \\
\text { No (\%) }\end{array}$ & $\begin{array}{l}\text { Controls } \\
\text { No (\%) }\end{array}$ & OR $(95 \% C I)$ & \\
\hline \multicolumn{5}{|l|}{ Cardiovascular disease: } \\
\hline Systemic hypertension & $760(41.5)$ & $636(34.8)$ & $1.33(1.17-1.53)$ & $1.28(1.09-1.50)$ \\
\hline Coronary artery disease & $247(13.5)$ & $168(9.2)$ & $1.56(1.26-1.93)$ & $1.31(1.02-1.68)$ \\
\hline Hypertension or coronary artery disease & $858(47.0)$ & $708(38.8)$ & $1.40(1.22-1.60)$ & \\
\hline Smoking (non-smoking $\left.{ }^{\star}\right)$ : & $1298(70.5)$ & $1341(72.9)$ & & \\
\hline Past & $340(18.5)$ & $296(16.1)$ & $1.24(1.02-1.51)$ & $1.12(0.90-1.41)$ \\
\hline Present & $202(11.0)$ & $203(11.0)$ & $1.06(0.84-1.33)$ & $1.09(0.83-1.42)$ \\
\hline Spherical equivalent (emmetropia $\left.{ }^{\star}\right)$ : & $352(23.3)$ & $419(27.8)$ & & \\
\hline Myopia & $252(16.7)$ & $277(18.4)$ & $1.08(0.87-1.36)$ & $0.99(0.78-1.25)$ \\
\hline Hyperopia & $904(59.9)$ & $812(53.8)$ & $1.34(1.12-1.59)$ & $1.33(1.11-1.59)$ \\
\hline Iris colour $\left(\right.$ dark $\left.^{\star}\right)$ : & $809(44.4)$ & $869(47.7)$ & & \\
\hline Light (blue, green, grey) & $1013(55.6)$ & $953(52.3)$ & $1.15(1.00-1.31)$ & $1.22(1.05-1.42)$ \\
\hline Lens (no lens opacities and no cataract surgery ${ }^{\star}$ ): & $728(39.9)$ & $915(50.2)$ & & \\
\hline Lens opacities & $1002(55.0)$ & $822(45.1)$ & $1.69(1.45-1.97)$ & \\
\hline Cataract surgery & $93(5.1)$ & $86(4.7)$ & $1.53(1.10-2.11)$ & \\
\hline Lens opacities or previous cataract surgery & $1095(60.1)$ & $908(49.8)$ & $1.68(1.45-1.95)$ & $1.55(1.31-1.84)$ \\
\hline
\end{tabular}

$\star$ Reference group for polychotomous variables.

between pairs of variables and the outcome of AMD. Two variables and their interaction were taken into consideration in a multivariate logistic model. In case of a significant interaction, the two variables and their interaction were used in the following step of the analysis. In case of non-significant interaction, the confounder status of a variable was ascertained when, after adjustment, the relation between the other variables and the outcome variable disappeared.

- After the elimination of confounding factors, all the remaining variables and their interactions were introduced in the analysis for a more comprehensive modelling of the data. The goal of such an analysis was to statistically adjust the estimated effects of each variable of the multivariate logistic model for the other independent variables.

\section{Results}

RESULTS FOR THE TOTAL POPULATION (1844 CASES) Univariate analysis (Table 5)

The odds ratio was 1.33 for systemic arterial hypertension, and 1.56 for coronary artery disease. Current smoking was not a risk factor for AMD, in contrast with a history of smoking $(\mathrm{OR}=1.24)$. Owing to missing values or imprecise answers as far as duration or amount of smoking was concerned, the relation between $\mathrm{AMD}$ and number of past years of smoking could not be studied in more detail. Odds ratio for hypermetropia was 1.34 , and 1.15 for light coloured irises. Lens opacities were generally mild in both cases and controls ( $81 \%$ with $1+$ only), but the odds ratio for presence of lens opacities or past history of cataract surgery was 1.68 .

Other factors, including profession and past medical history other than hypertension or coronary artery disease, did not have a significant association with AMD.

\section{Multivariate analysis (Table 5)}

Among the previously listed significant factors, past smoking history seemed less of an influence after logistic regression analysis was performed. Multivariate analysis thus confirmed the role of the remaining characteristics with quite similar odds ratios (arterial hypertension, $\mathrm{OR}=1.28$; coronary artery disease, $\mathrm{OR}=1.31$; hyperopia, $\mathrm{OR}=1.33$; light coloured irises, $\mathrm{OR}=1.22$; and lens opacities or previous cataract surgery, $\mathrm{OR}=1.55)$.

\section{RESULTS WITHIN THE VARIOUS CLINICAL GROUPS} (TABLE 6)

Drusen

The average age of the 496 patients with drusen was 70.8 years, with a high preponderance of women (70.8\%). A total of 408 patients $(79.6 \%)$ presented with hard drusen, isolated or confluent, and $231(45.2 \%)$ with soft drusen. In a quarter of the cases $(25.1 \%)$, the drusen were associated with depigmentation, and in one third of the cases $(36.6 \%)$ with hyperpigmentation.

Table 6 Significant risk factors according to the various clinical groups

\begin{tabular}{|c|c|c|c|c|}
\hline & \multicolumn{4}{|c|}{ Multivariate analysis } \\
\hline & Drusen $O R^{\star}$ & $\begin{array}{l}\text { Pigment epithelium } \\
\text { alterations } O R^{\star}\end{array}$ & $\begin{array}{l}\text { Geographic atrophy } \\
\text { OR }\end{array}$ & $\begin{array}{l}\text { Exudative } \\
\text { maculopathy } O R^{\star}\end{array}$ \\
\hline \multicolumn{5}{|l|}{ Cardiovascular disease: } \\
\hline Systemic hypertension & & $1.73(1.25-2.40)$ & & \\
\hline Coronary artery disease & NS & & $3.19(1.81-5.64)$ & $1.49(1.03-2.15)$ \\
\hline Hypertension or coronary artery disease & & & & \\
\hline \multicolumn{5}{|l|}{ Spherical equivalent (emmetropia†): } \\
\hline Myopia & $0.94(0.58-1.50)$ & NS & NS & $0.92(0.63-1.35)$ \\
\hline Hyperopia & $1.42(1.01-1.98)$ & & & $1.82(1.34-2.48)$ \\
\hline Lens opacities or previous cataract surgery & $1.78(1.28-2.46)$ & $1.80(1.24-2.59)$ & $1.78(1.23-2.59)$ & $1.44(1.09-1.89)$ \\
\hline
\end{tabular}

${ }^{\star} \mathrm{OR}$ all have $95 \% \mathrm{CI}$.

†Reference group for polychotomous variable. 
Hyperopia $(\mathrm{OR}=1.42)$ and the presence of lens opacities or past history of cataract surgery $(\mathrm{OR}=1.78)$ were significantly associated with drusen.

Alterations in retinal pigment epithelium

There were 333 patients with alterations of the $\mathrm{RPE}$; their average age was 72 years, and $65.8 \%$ were women. The majority of patients presented with a combination of depigmentation $(94.5 \%)$ and hyperpigmentation $(83.8 \%)$.

The only systemic risk factor associated with this group was hypertension $(\mathrm{OR}=1.73)$; smoking habits were not identified as risk factors. The only significant ocular risk was the presence of lens opacities or past history of cataract surgery $(\mathrm{OR}=1.80)$. Hyperopia or light coloured irises were not significant risk factors.

Geographic atrophy ( $G A)$

A total of 343 cases were classified as GA; $71.4 \%$ of these patients were women. Drusen were associated with GA in $73.8 \%$ of the cases, and RPE hyperpigmentation in $67.3 \%$; hypopigmentation was rare $(12.5 \%$ cases $)$. The average age of patients with GA was 74.3 years, making this the oldest subgroup.

A search for confounding factors showed a high link between systemic hypertension and coronary artery disease $(\mathrm{p}<0.001)$. Multivariate analysis yielded the following results: coronary disease, $\mathrm{OR}=3.19$; and lens opacities or previous cataract surgery, $\mathrm{OR}=1.78$.

\section{Exudative AMD}

A total of 672 eyes presented with exudative AMD. Mean age was 73.8 years, and $65.7 \%$ were female. Most eyes harboured occult CNV $(72.6 \%)$, whereas approximately one third $(29.7 \%$ ) had well defined CNV and $16 \%$ a vascularised pigment epithelium detachment (PED). Drusen surrounded the exudative lesion in $363(54.4 \%)$ of the eyes. RPE mottling, depigmentation, and atrophy were still visible in $33.2 \%, 13.5 \%$, and $16.7 \%$ of eyes, respectively.

Multivariate analysis identified coronary artery disease $(\mathrm{OR}=1.47)$, hypermetropia $(\mathrm{OR}=1.83)$, and lens opacities or previous cataract surgery $(\mathrm{OR}=1.44)$ as risk factors for exudative AMD.

\section{Discussion}

Several prospective, population based, or casecontrol studies have examined the risk factors for AMD. Clinical systemic factors for this study were chosen based on contradictory published data in the literature - that is, hypertension, past history of coronary diseases, and smoking habits. This study is the first casecontrol study concerning systemic and ocular risk factors performed in Western Europe.

AGE

The mean age of patients in the groups with drusen and with RPE alteration was 70.8 and 72.0 years, respectively. In late stages, the mean age was 73.8 for the exudative form and 74.3 for the atrophic form, which confirms the link between severity of AMD and aging.

\section{SYSTEMIC HYPERTENSION}

Systemic hypertension was found to be significant by multivariate analysis when the global population was considered $(\mathrm{OR}=1.26)$. In the Framingham Eye Study, ${ }^{3}$ Sperduto and Hiller reported an association between AMD and systemic hypertension (that is, diastolic pressure higher than $95 \mathrm{~mm} \mathrm{Hg}$ ). While the National Health and Nutrition Examination Survey showed higher mean systolic blood pressure in patients with $\mathrm{AMD}$, no significant statistical link was established. ${ }^{4}$ In their casecontrol study, Hyman et $a l^{5}$ reported a lack of association between AMD and systemic hypertension when considered alone.

In contrast with Vidaurri et $a l,{ }^{6}$ we could not establish any relation between systemic hypertension and drusen, thus concurring with the findings of the Beaver Dam Eye Study, ${ }^{7}$ although an association was found for systemic hypertension and RPE alterations $(\mathrm{OR}=1.73)$. In patients with GA, an association with systemic hypertension was established only with univariate analysis, owing to a strong correlation with coronary artery disease. During the exudative stage of the disease, hypertension, previously reported to be significantly associated with exudative macular degeneration, ${ }^{8}$ was not identified as a risk factor in this study or in the Beaver Dam Eye Study. ${ }^{7}$

CORONARY ARTERY DISEASE

A strong relation was found between coronary artery disease and advanced forms of AMD. The OR was 3.30 with multivariate analysis in patients with GA; in patients with exudative disease the OR was 1.5. This association was suggested previously by Hyman et al in two reports. ${ }^{58}$

While more recent studies did not identify coronary artery disease as a risk factor for $\mathrm{CNV}$, they did suggest the possible influence of a cardiovascular risk factor profile on the incidence of CNV, including increased cholesterol level and exogenous estrogen intake, ${ }^{9}$ haematocrit values, and leucocyte counts.

SMOKING

A history of smoking was associated with AMD $(\mathrm{OR}=1.24)$, but only on univariate analysis for the total population. In each subgroup, OR values were quite similar but not significant.

Smoking has been related to a higher incidence of ARM in several studies. ${ }^{10}{ }^{11}$ In a study by Hyman et $a l,{ }^{5} 83 \%$ of patients with AMD were smokers, in comparison with $65 \%$ in the control group, but this was significant only for men.

A study by Shiraga et $a l^{12}$ showed a dependent relation between number of cigarettes smoked and AMD; similarly, Vingerling et al ${ }^{13}$ provided evidence for a dose-response relation between smoking and AMD, particularly for the neovascular form. 
Other studies, ${ }^{214}{ }^{16}$ however, were not able to prove that smoking was a risk factor for the development of AMD.

IRIS COLOUR

Hyman and colleagues ${ }^{58}$ and Weiter et $a l^{17}$ found that subjects with lightly and moderately pigmented irises were at higher risk of progression of AMD to late stages, in comparison with individuals with heavily pigmented irises. Our study, as well as the Eye Disease Case-Control Study Group, ${ }^{9}$ did not find a statistically significant association in any subgroup.

\section{CATARACT}

Lens opacities were significantly associated with all forms of AMD in our study. OR on multivariate analysis was highest for RPE alterations (1.80), geographic atrophy (1.67), and drusen (1.74), and slightly less for exudative forms (1.44). Because of the large number of investigators, classification of these cataracts into different anatomic forms was not performed.

Recently, Klein et $a l^{18}$ found a similar association between nuclear sclerosis and early stages of AMD, including drusen and RPE alterations $(\mathrm{OR}=1.96)$, but no association with late stages of AMD (GA and the exudative form). That study differentiated nuclear sclerosis from cortical and subcapsular cataracts, and found that the latter forms were not related to either early or late stages of AMD.

Sperduto et $a l^{19}$ found contrasting results, with an increased incidence of AMD in the presence of cortical lens changes and a decreased incidence of AMD with nuclear sclerosis.

\section{HYPEROPIA}

Hyperopia was demonstrated to be a risk factor in the global population $(\mathrm{OR}=1.33)$ and in patients with the exudative forms of AMD $(\mathrm{OR}=1.83)$. This has been reported previously by several authors. ${ }^{5} 9141520$

Previous epidemiological studies focused on the differentiation of dry and exudative forms. On the other hand, a refined classification of AMD was used in referral centres. In this study, recruitment of cases was based on nonselected ophthalmological practice, to avoid bias of referral centres. In addition, this study, which is based on angiographic features for AMD, provides the respective proportion of each form.

In conclusion, our large case-control study, which we believe reflects a cross section of the entire population of France, suggests a relation between AMD and hypertension, coronary artery disease, light coloured irises, hyperopia, lens opacities, or history of cataract surgery. Moreover, the significance of vascular risk factors is increased for late stages of AMD, especially the atrophic forms. The impact of these risk factors on the evolution of AMD must be studied by long term follow up of these patients.

This study was supported by grants from Biopharma and Servier Laboratories.
Scientific committee: H Bourgeois (Paris), G Chaine (Bobigny), A Hullo (Lyon), J Sahel (Strasbourg), G.Soubrane (Créteil).

Regional coordinators: B Arnaud (Montpellier), F Bacin (Clermont-Ferrand), A Béchetoille (Angers), M Boissonnot (Poitiers), H Bourgeois (Paris), G Brasseur (Rouen), A Bron (Dijon), A Catros (Rennes), J Colin (Brest), G Constantinidès (Lille), M Dominguez (Bordeaux), P Gastaud (Nice), P Gayet Nantes), X Graftiaux (Angers), A Hullo (Lyon), P Labalette (Nantes), X Graftiaux (Angers), A Hullo (Lyon), P Labalette (Lille), F Malecaze (Toulouse), M Montard (Besançon), Mouillon (Grenoble), M Quéré (Nantes), A Raspiller (Nancy), B Ridings (Marseille), A Robinet (Brest), C Rossazza
(Tours), J F Rouland (Lille), J Sahel (Strasbourg), P J Toulemont (Rennes), P Turut (Amiens)

1 Young RW. Pathophysiology of age-related macular degeneration. Surv Ophthalmol 1987;31:291-305.

2 Leibowitz HM, Krueger DE, Maunder LR, et al. The Framingham Eye Study Monograph. Surv Ophthalmol 1980;24(suppl):343-65

3 Sperduto RD, Hiller R. Systemic hypertension and agerelated maculopathy in the Framingham Study. Arch Ophthalmol 1986;104:216-19.

4 Goldberg J, Flowerdew G, Smith E, et al. Factors associated with age-related macular degeneration: an analysis of data from the first National Health and Nutrition Examination Survey Am 7 Epidemiol 1988:128:700-10.

5 Hyman LG, Lilienfeld AM, Ferris FL, et al. Senile macular degeneration: a case-control study. Am $\mathcal{f}$ Epidemiol. 1983;118:213-27.

6 Vidaurri JS, Pe'er J, Halfon ST, et al. Association between drusen and some of the risk factors for coronary artery disdrusen and some of the risk factors for

7 Klein R, Klein BEK, Franke T. The relationship of cardiovascular disease and its risk factors to age-related maculopathy. The Beaver Dam Eye Study. Ophthalmology 1993;100:406-14

8 Hyman L, He O, Grimson R, et al. Risk factors for age-related maculopathy. Invest Ophthalmol Vis Sci 1992; 33(suppl):801.

9 The Eye Disease Case-Control Study Group. Risk factors for neovascular age-related macular degeneration. Arch Ophthalmol 1992;110:1701-8.

10 Paetkau ME, Boyd Tas, Grace M, et al. Senile disciform macular degeneration and smoking. Can $\mathcal{F}$ Ophthalmol 1978;13:67-71

11 Klein R, Klein BEK, Linton KLP, et al. The Beaver Dam Eye Study: the relation of age-related maculopathy to Eye Study: the relation of age-related macu

12 Shiraga F, Matsuo N, Katayama S, et al. Neovascular ge-related macular degeneration. A case control study. Folia Ophthalmol fpn 1987;38:525-33.

13 Vingerling JR, Dielemans I, Hofman A, et al. Age-related macular degeneration and smoking: the Rotterdam Study. Invest Ophthalmol Vis Sci 1995;36(suppl):59.

14 Maltzman BA, Mulvihill MN, Greenbaum A. Senile macular degeneration and risk factors: a case-control study. Ann Ophthalmol 1979;11:1197-201.

15 Delaney WV, Oates RP. Senile macular degeneration: a preliminary study. Ann Ophthalmol 1982;14:21-4.

16 Blumenkranz MS, Russell SR, Robey MG, et al. Risk factors in age-related maculopathy complicated by choroidal neovascularization. Ophthalmology 1986;93:552-8

17 Weiter JJ, Delori FC, Wing GL, et al. The relationship of senile macular degeneration to ocular pigmentation. $A m \mathcal{F}$ Ophthalmol 1985;99:185-7.

18 Klein R, Klein BEK, Wang Q, et al. Is age-related maculopathy associated with cataracts? Arch Ophthalmol
mate 1994;112:191-6.

19 Sperduto RD, Hiller R, Seigel D. Lens opacities and senile maculopathy. Arch Ophthalmol 1981;99:1004-8.

20 Sandberg MA, Tolentino MJ, Miller S, et al. Hyperopia and neovascularization in age-related macular degeneration. Ophthalmology 1993;100:1009-13.

21 Ferris FL. Senile macular degeneration: a review of epidemiologic features. Am f Epidemiol 1983;118:132-51

22 Klein R, Davis MD, Magli YL, et al. The Wisconsin age-related maculopathy grading system. Ophthalmology 1991;98:1128-34.

23 AREDS. Age-related eye disease study protocol summary. Madison, Wisconsin, 1991.

24 Bird AC, Bressler NM, Bressler SB, et al. The international classification and grading system for age-related maculopathy and age-related macular degeneration. Surv Ophthalmol 1995;39:367-74.

25 Gass JDM. Stereoscopic atlas of macular diseases. Diagnosis and treatment. 3rd ed. St Louis: CV Mosby, 1987.

26 Coscas G, Glaser B, Green WR, et al. Drusen. In: Coscas G, ed. Dégénérescences maculaires acquises liées à l'âge et néovaisseaux sous-rétiniens. Paris: Masson, 1992:153-89.

27 Soubrane G. In: Soubrane G, Coscas G, ed. Principaux types d'altération de l'épithélium pigmentaire dans les affections acquises de l'épithélium pigmentaire rétinien. Marseilles: Lamy, 1995:239.

28 Sarks S, Sarks J. Age-related macular degeneration: atrophic form. In: Ryan SJ, ed. Retina. 2nd ed. St Louis: Mosby, 1994:1071-102.

29 Gass JDM. Pathogenesis of disciform detachment of the neuro epithelium IV. Fluorescein angiographic study of senile disciform macular degeneration. Am ₹ Ophthalmol 1967;63:644-59.

30 Soubrane G, Coscas G, Français C, et al. Occult subretinal neovessels in age-related macular history: natural history and early laser treatment. Ophthalmology 1990;97:647-9. 
31 Macular Photocoagulation Study Group. Subfoveal neovascular lesions in age-related macular degeneration: guidelines for evaluation and treatment in the Macular Photocoagulation Study. Arch Ophthalmol 1991;109:1242-57.

32 Ryan SJ, Stout JP, Dugel PU. Subretinal neovascularization. In: Ryan SJ, ed. Retina. St Louis: Mosby, 1994:1027-47.
33 Gass JDM. Serous retinal pigment epithelium detachment with a notch a sign of occult choroidal neovascularization. Retina 1984;4:205-20.

34 Hosmer DW, Lemeshow S. Applied logistic regression. New York: Wiley, 1989:187-201.

\section{British fournal of Ophthalmology - http://www.bjophthalmol.com}

Visitors to the world wide web can now access the British fournal of Ophthalmology either through the BMJ Publishing Group's home page (http://www.bmjpg.com) or directly by using its individual URL (http://www.bjophthalmol.com). There they will find the following:

- Current contents list for the journal

- Contents lists of previous issues

- Members of the editorial board

- Information for subscribers

- Instructions for authors

- Details of reprint services.

A hotlink gives access to:

The web site is at a preliminary stage and there are plans to develop it into a more sophisticated site. Suggestions from visitors about features they would like to see are welcomed. They can be left via the opening page of the BMJ Publishing Group site or, alternatively, via the journal page, through "about this site".
- BMJ Publishing Group home page

- British Medical Association web site

- Online books catalogue

- BMJ Publishing Group books. 